\title{
Protective Efficacy of a Commercial Live Attenuated aroA mutant Vaccine Against Avian Pathogenic Escherichia coli Challenge in Broilers
}

\author{
Ahlam A. Gharib ${ }^{1}$, Ahmed M. Hamouda ${ }^{2}$, Ashraf A.M. Abdel-Wahab ${ }^{1}$ and Mohammed F. \\ Fawzy $^{1 *}$ \\ ${ }^{1}$ Microbiology Department, Faculty of Veterinary Medicine, Zagazig University, 44511, Egypt \\ ${ }^{2}$ Microbiology Department, Animal Health Research Institute, Zagazig Branch, Egypt
}

\begin{abstract}
Avian colibacillosis is an infectious disease of domestic poultry with economic importance. Among the tools available for the control avian pathogenic E. coli (APEC), vaccines have received the most attention. In this research, comparative bacteriological examination between candidates of live aroA mutant E. coli vaccine and two virulent APEC strains (O78 and O125) was carried. Innate immunity (leukogram \& Phagocytosis) as well specific cellular (CD4 \& CD8) and humoral (agglutinins) immune response of vaccinated chickens were evaluated. Also the mortality rate, colibacillosis lesions and bacterial re-isolation were detected after challenge to stand upon their minimizing in vaccinated chickens. The comparative study demonstrated that the vaccinal and virulent strains were similar in respect of colony morphology, biochemical reactions, Congo red binding and motility but were differ in antimicrobial sensitivity pattern as well inability of vaccinal strain to grow on minimal agar medium. The immune correlate of aroA mutant E. coli vaccine protection is linked to cell mediated immunity not to circulating antibodies. Finally, it could concluded that spraying of aroA mutant vaccine provide virtually protective efficacy in broiler chickens against homologous APEC O78 challenge and had not a significant values against heterologous strain, although it is safe as alternative to chemotherapeutics.
\end{abstract}

Keywords: Chickens, Avian pathogenic Escherichia coli, aroA mutant, Vaccine.

\section{Introduction}

Avian pathogenic Escherichia coli (APEC) infections caused considerable economic losses in poultry industry worldwide [1]. APEC is part of the normal microflora of the intestinal tract and other mucosal surfaces of domestic poultry and wild-birds. It is mostly associated with extraintestinal diseases, mainly respiratory or systemic infections [2]. APEC belongs to several serotypes, including O1, $\mathrm{O} 2, \mathrm{O} 78$, O8, and $\mathrm{O} 35$, which share several virulence characteristics [3].

Colisepticemia is the most hazard impact of avian pathogenic E. coli infection which mostly starts as an upper respiratory tract infection after combination with other pathogenic agents leading to chronic respiratory disease [3]. In addition, a possible association between $E$. coli - contaminated poultry meat and human infections has been proposed because the virulence factors found in E. coli strains that cause neonatal meningitis or urinary tract infections also are present in many APEC strains [4]. E. coli antimicrobial resistance becomes a sophisticated issue due to restrictions proposed by regulatory organizations that give approval of using few antibiotics, as well as it becomes very difficult to discover new antibiotics for the control of these resistant E. coli [5]. Consequently, vaccines have recently projected to be the most attractive solution to control avian pathogenic E. coli infection [6]. Several reports have described attempts to evaluate the efficacy of $E$. coli subunit vaccine [7,8], whole-cell-inactivated vaccine $[9,10]$, live attenuated vaccine [6,11], and vectored vaccine $[12,13]$ in chickens and turkeys. The poultry industry requires inexpensive vaccine candidates that can be easily administered, and the live attenuated bacterial vaccines fulfill both criteria. In addition, they may also have the benefit of providing naive day-old chicks with a resident gut flora that may provide a degree of competitive exclusion against other bacterial pathogens [6]. Studies using liveattenuated bacteria as vaccine candidates have resulted in one commercial product; O78:K80 aroA mutant $E$. coli. This vaccine has the efficacy in particular against heterologous $E$.

*Corresponding author email: (mohamed.fouad.fawzy.86@gmail.com), Microbiology Department, 366 Faculty of Veterinary Medicine, Zagazig University, 44511, Egypt. 
coli and consequently it required thorough investigation under field conditions [14].

This study aimed to evaluate the efficacy of a commercial live attenuated $E$. coli vaccine against homologous and heterologous APEC challenge to stand up on, lesions, mortality rate and bacterial re-isolation. Hopefully, to minimize the multi-drug resistant $E$. coli carriage in chickens.

\section{Materials and Methods}

\section{Bacterial strains}

Vaccinal strain (Poulvac® E. coli), freezedried, live attenuated vaccine prepared from an O78:K80 aroA mutant E. coli strain EC34195, for poultry use was supplied by Zoetis. One dose contains: $5.2 \times 10^{6}$ to $9.1 \times 10^{8} \mathrm{CFU} /$ chick, another two field virulent isolates were isolated from the liver of naturally infected chickens, serogrouped as $\mathrm{O} 78$ and $\mathrm{O} 125$ and were obtained from Bacteriology Department, Animal Health Research Institute, Zagazig, Egypt. Freeze-dried vaccines were rehydrated with PBS and diluted to yield the desired dose in water.

\section{Comparative bacteriological characterization}

The vaccine aroA mutant $E$. coli strain and the two virulent isolated strains $(\mathrm{O} 78$ \& $\mathrm{O} 125)$ were tested for morphological, cultural and biochemical characteristics [15]. As well, growth on both sheep blood agar and the minimal medium (Sigma-Aldrich-79332) [6]. The antimicrobial susceptibility test was performed [16]. Congo Red (Sigma-Aldrich co., st-louis, Mo, USA) binding ability and motility test were done [17]. Further, slide agglutination [18] was performed to detect virulence determinants associated with vaccinal and isolated strains. Finally, O-serogrouping was carried out (DENKA SEIKEN Co., LTD, 3-4.2 Nihonbashi kaya-Cho, Chuo$\mathrm{Ku}$, and Tokyo, Japan).

\section{Experimental chickens}

Three hundred commercial day-old broiler chicks (Cobb) were obtained from a local hatchery and maintained in pens at the animal husbandry facilities of Faculty of Veterinary Medicine, Zagazig University, Egypt, following the guideline the Committee of Animal Welfare and Research Ethics, Faculty of Veterinary Medicine, Zagazig University. The chickens were fed ad libitum with neither antibacterial nor anticoccidial components in their feed. These birds were bacteriologically tested to confirm that, they are free from $E$. coli infection.

\section{Experimental design}

The chickens were divided equally into three experimental designs (100 chicks each). The experimental design I was used for immunological assessment while designs II and III were used for assessment of the protection against homologous and heterologous $E$. coli challenge, respectively. Each design was randomly assigned into three chicken groups: group 1, Chickens (35) vaccinated once at $1^{\text {st }}$ day of age; group 2, Chickens (35) vaccinated twice at $1^{\text {st }}$ and $14^{\text {th }}$ days of age and group 3, contained unvaccinated chickens (30). All the chicks in test groups 1 and 2 in the experimental designs were vaccinated by spraying method with a dose containing $5.2 \times 10^{6}-9.1 \times 10^{8} \mathrm{CFU} /$ chick either at $1^{\text {st }}$ or $14^{\text {th }}$ days of age according vaccine administration manufacture's guideline.

\section{Immunological assessment of vaccinated chickens}

The chickens in experimental design I were vaccinated (groups $1 \& 2$ ). The chickens were monitored daily for signs of illness and death. All birds were weighted and blood samples of the three groups were collected at days $1,7,14$ and 21 post vaccination (pv) to evaluate their immune-responses against $E$. coli vaccine. Surviving chickens were sacrificed at day 21 pv, macroscopic lesions were recorded [11] and bacterial culture from air sacs, liver and heart were performed for qualitative assessment.

\section{Leukogram}

Absolute blood cell count analysis was performed at Clinical Pathology Department, Animal Health Research Institute, Zagazig Branch, Egypt, using Sysmex 2000iV for total and differential leukocytic counts.

\section{Phagocytosis activity of peripheral blood monocyte cell (PBMC)}

Measurement of phagocytic activity of PBMC using Candida albicans was adapted as described previously $[19,20]$ and performed at 
Clinical Pathology Department, Animal Health Research Institute, Zagazig Branch, Egypt.

\section{Tube agglutination test}

Two-fold serial dilution of each serum sample was carried out using nine clean dry tubes containing a diluent of $0.9 \% \mathrm{w} / \mathrm{v}$ of $\mathrm{NaCl}$ sterile solution [21]. In the first tube 0.1 $\mathrm{mL}$ of serum was mixed with a $0.9 \mathrm{~mL}$ of diluent and then $0.5 \mathrm{~mL}$ of diluted serum was transferred to a second tube containing $0.5 \mathrm{~mL}$ of a diluent. It was continued till the 1:64 dilution of serum obtained. Finally, $0.5 \mathrm{~mL}$ of whole cell antigen suspension of $E$. coli was added to each tube. Two tubes, containing separately antigen suspension and a sterile solution of $0.9 \% \mathrm{w} / \mathrm{v}$ of $\mathrm{NaCl}$, were used as positive and negative control, respectively. The last dilution with visible agglutination was recorded.

\section{Cell mediated Immunity assessment using flow} cytometry technique

Using a method described previously [11], approximately $2 \mathrm{~mL}$ of blood were collected from the brachial wing veins or by heart puncture (only for the newly hatched chicks) using heparinized syringes and were transferred into tubes containing heparin. Blood samples were processed within $1 \mathrm{~h}$ of collection. Leukocytes were purified from the blood and assayed using the flow cytometry technique as described below. The tested parameters through flow cytometry were CD4 and CD8 T lymphocytes.

Mononuclear cells were separated from whole blood by density gradient using Ficoll (Histopaque-1077H; Sigma-Aldrich, St. Louis, $\mathrm{MO}$ ), as following: Blood was diluted 1:1 in PBS ( $\mathrm{pH}$ 7.4) to a final volume of $2 \mathrm{~mL}$. This dilution was added to the top of $1 \mathrm{~mL}$ of Ficoll in $15 \mathrm{~mL}$ conic sterile tube. The samples were centrifuged in an Eppendorf $5804 \mathrm{R}$ centrifuge at $2000 \mathrm{rpm}$ for $30 \mathrm{~min}$ with no break at room temperature. The resulting buffy coat was collected and then transferred to another 15 $\mathrm{mL}$ tube. The cells were washed twice with 4 $\mathrm{mL}$ PBS and centrifuged at $2000 \mathrm{rpm}$ for 7 min. The final cells pellet was re-suspended in $1 \mathrm{~mL}$ of $1 \%$ paraformaldehyde (SigmaAldrich) in PBS for cell fixation. Thirty minutes after re-suspension, the cells were centrifuged at $2000 \mathrm{rpm}$ for $7 \mathrm{~min}$, the supernatant was discarded, and the cells were washed twice with PBS and centrifuged under the same conditions. The final pellet was resuspended in PBS with $1 \%$ bovine serum albumin (Sigma-Aldrich).

For flow cytometry, single staining was performed for all antibodies using the concentrations recommended by the manufacturer (GeneTex International Corporation). The dilution was mixed with $10^{6}$ mononuclear cells and kept at room temperature (at about $25^{\circ} \mathrm{C}$ ) in the dark for 20 min. After incubation, the cells were washed with $2 \mathrm{~mL} \mathrm{PBS}$, centrifuged at $2000 \mathrm{rpm}$ for 7 $\mathrm{min}$. The final pellet was re-suspended in 1000 $\mathrm{mL}$ of PBS. All samples were gone through flow cytometry within $4 \mathrm{~h}$ of labeling on a FACS (fluorescein antibody cell sorting) CaliburH flow cytometer (Becton Dickinson). Green fluorescence-isothiocyanate (FITC) was detected in the FL1 channel (nm 530/ 30), and yellow fluorescence (PE) was detected in the FL2 channel (nm 585/42). Cells were analyzed on at least 10,000 events at the lymphocyte gate based on forward and side scatters, which include contaminant thrombocytes, which have a very similar morphology to lymphocytes. Data were analyzed with FlowJo ${ }^{\circledR}$ software (TreeStar, Inc).

\section{Assessment of protection against challenge}

The protective ability of aroA mutant $E$. coli vaccine was assessed against $E$. coli challenge of both homologous (O78) and heterologous (O125) strains [6].

The three chicken groups of each experimental designs II and III were separately challenged at 21 day old by intra-tracheal route with $1 \mathrm{~mL}$ containing $9 \times 10^{8} \mathrm{CFU} /$ chick (gradually inoculated) of APEC O78 and $\mathrm{O} 125$ serotypes, respectively. After challenge, all birds were observed daily for 7 days; all mortalities during the observation period were necropsied. The surviving chickens at the end of the challenge period were all euthanatized, necropsied, and examined for colibacillosis lesions, also bacterial re-isolation was performed.

Preparation of E. coli suspensions for challenge were carried out according to $\mathrm{La}$ Ragione et al. [6]. The challenge E. coli strains were plated onto tryptic soy agar plates the 
night before the challenge. On the day of challenge, well-isolated colonies from TSA plates were inoculated into brain heart infusion broth and incubated at $37{ }^{\circ} \mathrm{C}$ with agitation for 2-4 $\mathrm{h}$ and then diluted in PBS to yield an approximate concentration of $9 \times 10^{8} \mathrm{CFU} / \mathrm{mL}$.

\section{Statistical analysis}

The data were analyzed using the statistical package program SPSS version 23 Software for Windows (IBM Corp. Released 2013). One-way ANOVA test as parametric test as well as Kruskal-Wallis test as non-parametric test were used for comparison between different groups. The $\mathrm{p}$-value $\leq 0.05$ was considered statistically significant.

\section{Results}

\section{Bacteriological characterization of aroA mutant E. coli}

Morphological characteristics of the aroA mutant E. coli showed a Gram-negative, uniform staining, non-spore forming bacilli, typical bright pink colonies on MacConkey's agar, alpha hemolysis on sheep blood agar and a green metallic sheen colonies on eosinmethylene blue agar, but unable to grow on the minimal agar medium, while both field strains were able to grow. Biochemical identification of aroA mutant $E$. coli, showed positive indole and methyl red reaction, while it was negative for citrate and Voges Proskauer tests. The aroA mutant E. coli strain was able to bind Congo red and it was motile as grew away from line of stabbing into semisolid agar. It was sero-grouped as $\mathrm{O} 78$ while the other strains were $\mathrm{O} 78$ and $\mathrm{O} 125$. Antimicrobial susceptibility test showed that the aroA mutant $E$. coli is susceptible to cefotaxime, ciprofloxacin, chloramphenicol, trimethoprim amoxicillin, doxycycline and gentamicin but resistant to erythromycin, while other two strains $\mathrm{O} 78$ and $\mathrm{O} 125$ were multidrug resistant.

\section{Immune-responses assessment}

Attenuation and safety of aroA mutant E. coli

Neither mortalities nor colibacillosis like lesions were observed in the three tested groups of experimental design I. There was no significant difference in average body weight during the first three weeks of age between the three tested groups. The estimation of this trial indicated that aroA mutant $E$. coli vaccine was safe in chickens.

\section{Innate immune-response assessment:}

The leukogram results showed that there were no significant differences between total or differential leukocytic count during the first three weeks old of vaccinated or nonvaccinated groups. As well as, the Phagocytic $\%$ and phagocytic index of chicken PBMC for C. albicans at 1, 7, 14 and 21day post vaccination in the three test groups of experimental design I had no significant differences.

\section{Humoral immunity assessment}

Tube agglutination test showed that there was no significant difference in the antibody response between the vaccinated groups and non-vaccinated group. No agglutination was observed in both vaccinated and nonvaccinated groups at 1,7,14 and 21 days pv.

\section{Cell mediated Immunity assessment}

The cytometry assay performed on one day pv, showed differences between the test groups. An increase in the cell percentages of CD4, CD8 and ratio of CD4:CD8 was recorded in the vaccinated groups (1 and 2) in comparison to non-vaccinated group. On $7^{\text {th }}$ day pv, no differences among vaccinated groups were observed, where the increase that was observed among vaccinated groups at 1 day old pv was gradually decreased and no longer present. On day 14 and similarly 21 pv, there was an increase in the number of CD4 as well CD8 $\mathrm{T}$ lymphocytes separately in the vaccinated group in comparison to unvaccinated group. Such data are demonstrated in Figure (1). 


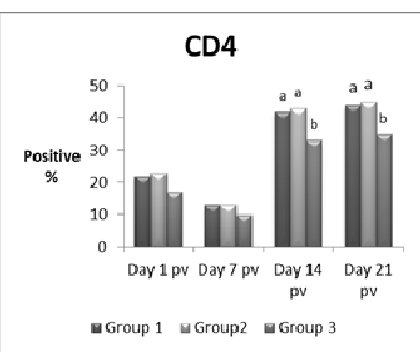

A

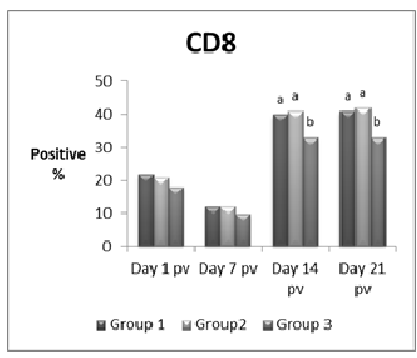

B

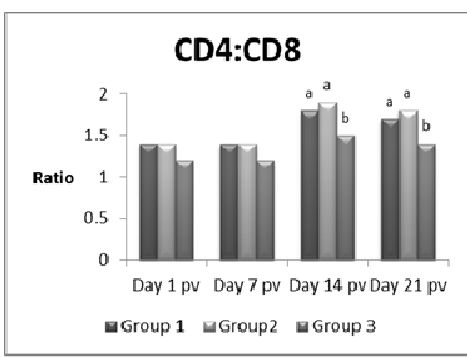

C

Figure 1: A histogram of chicken T-lymphocytes in three tested groups post vaccination with aroA mutant $E$. coli A: CD4 subpopulation; B: CD8 subpopulation; C: CD4:CD8 Ratio. Letters a \& b indicate statistically differences between groups $(\mathbf{P}<0.05)$.

\section{Assessment of protection against challenge}

Assessment of the protection against homologous challenge

During the observation period, 7-day post challenge, none of the vaccinated chickens (groups 1 and 2) died in spite of two chickens died in group 2 prior to challenge, whereas $10 \%$ of un-vaccinated chickens died in group 3 . The cumulative colibacillosis rates one week after challenge in groups 1, 2 and 3 were $28.6 \%, 27.3 \%$ and $93.3 \%$ respectively. Macroscopic lesions including perihepatitis, pericarditis and airsaculitis were $(20 \%, 8.6 \%$ and $22.9 \%)$, (18.1\%, 6\% and $24.2 \%$ ) and $(83.3 \%, 80 \%$ and $90 \%)$ for groups 1,2 and 3 , respectively as showed in Table (1). Bacterial re-isolation indicated that $E$. coli $\mathrm{O} 78$ percentage in groups $1-3$ were $31.4 \%, 30.3 \%$ and $100 \%$, respectively. These estimates indicated that both doses of the vaccine induced significant protection against homologous colibacillosis challenge.

\section{Assessment of the protection against} heterologous challenge

During the 7-day post challenge observation period, neither the vaccinated (groups 1 and 2) nor un-vaccinated (group 3) chickens died, in spite of one chicken in each of groups (1) and (2) and three un-vaccinated chickens of group (3) died prior to challenge. The cumulative colibacillosis mortality rates one week after challenge in groups 1, 2 and 3 were $67.6 \%, 61.8 \%$ and $77.8 \%$ respectively. Macroscopic lesions including perihepatitis, pericarditis and airsaculitis were (44.1\%, $32.4 \%$ and $50.0 \%),(41,2 \%, 44,1 \%$ and $41.2 \%)$ and $(66.7 \%, 40.7 \%$ and $74.1 \%)$ for groups 1,2 and 3, respectively as showed in Table (2). Bacterial re-isolation indicated that $E$. coli O125 percentage in groups $1-3$ were $73.5 \%$, $67.6 \%$ and $100 \%$, respectively.

Table 1: Mortality and macroscopic lesion rates of vaccinated and none vaccinated chickens in different groups 7 days post homologous $E$. coli $(\mathrm{O} 78)$ challenge

\begin{tabular}{|c|c|c|c|c|c|c|}
\hline \multirow[b]{2}{*}{ Group } & \multirow[b]{2}{*}{ Vaccination* } & \multirow[b]{2}{*}{$\begin{array}{l}\text { Mortality \% } \\
\text { (No. of } \\
\text { dead/Total) }\end{array}$} & \multicolumn{3}{|c|}{$\begin{array}{c}\text { Macroscopic lesions\% } \\
\text { (No. of macroscopic lesion/Total) }\end{array}$} & \multirow[b]{2}{*}{$\begin{array}{c}\text { Cumulative } \\
\text { colibacilliosis\%*** } \\
\text { (No. of Positive/Total) }\end{array}$} \\
\hline & & & Perihepatitis & Pericarditis & Airsaculitis & \\
\hline 1 & $\begin{array}{c}\text { Once } \\
\text { vaccination }\end{array}$ & $0(0 / 35)^{\mathrm{a}}$ & $20(7 / 35)^{\mathrm{a}}$ & $8.6(3 / 35)^{\mathrm{a}}$ & $22.9(8 / 35) \mathrm{a}$ & $28.6(10 / 35)^{\mathrm{a}}$ \\
\hline 2 & $\begin{array}{c}\text { Twice } \\
\text { vaccination }\end{array}$ & $0(0 / 33)^{* * a}$ & $18.1(6 / 33)^{\mathrm{a}}$ & $6(2 / 33)^{\mathrm{a}}$ & $24.2(8 / 33) \mathrm{a}$ & $27.3(9 / 33)^{\mathrm{a}}$ \\
\hline 3 & No vaccination & $10(3 / 30)^{\mathrm{a}}$ & $83.3(25 / 30)^{b}$ & $\begin{array}{c}80 \\
(24 / 30)^{b}\end{array}$ & $90 \quad(27 / 30)^{b}$ & $\begin{array}{c}93.3 \\
(28 / 30)^{\mathrm{b}}\end{array}$ \\
\hline
\end{tabular}

*: Vaccination by spray method.

**: Two chickens died in group 2 prior to challenge.

***: Total of all birds dying after challenge or showing any of the gross lesions listed.

Values with different letters in the same column differ significantly $(\mathrm{P}<0.05)$ 
Table 2: Mortality and macroscopic lesion rates of vaccinated and none vaccinated chickens in different groups 7 days post heterologous $E$. coli $(0125)$ challenge

\begin{tabular}{|c|c|c|c|c|c|c|}
\hline \multirow[b]{2}{*}{ Group } & \multirow[b]{2}{*}{ Vaccination* } & \multirow[b]{2}{*}{$\begin{array}{l}\text { Mortality\% } \\
\text { (No. of } \\
\text { dead/Total) }\end{array}$} & \multicolumn{3}{|c|}{$\begin{array}{c}\text { Macroscopic lesions\% } \\
\text { (No. of macroscopic lesion/Total) }\end{array}$} & \multirow[b]{2}{*}{$\begin{array}{c}\text { Cumulative } \\
\text { colibacilliosis \%*** } \\
\text { (No. of Positive/Total) }\end{array}$} \\
\hline & & & Perihepatitis & Pericarditis & Airsaculitis & \\
\hline 1 & $\begin{array}{c}\text { Once } \\
\text { vaccination }\end{array}$ & $0(0 / 34) * *^{\mathrm{a}}$ & $44,1(15 / 34)^{\mathrm{a}}$ & $32.4(11 / 34)^{\mathrm{a}}$ & $50.0(17 / 34)^{\mathrm{a}}$ & $67.6(23 / 34)^{\mathrm{a}}$ \\
\hline 2 & $\begin{array}{c}\text { Twice } \\
\text { vaccination }\end{array}$ & $0(0 / 34)^{* *^{a}}$ & $41,2(14 / 34)^{\mathrm{a}}$ & $44,1(15 / 34)^{\mathrm{a}}$ & $41.2(14 / 34)^{\mathrm{a}}$ & $61,8(21 / 34)^{\mathrm{a}}$ \\
\hline 3 & No vaccination & $0(0 / 27)^{*} *^{\mathrm{a}}$ & $66.7(18 / 27)^{\mathrm{a}}$ & $40.7(11 / 27)^{\mathrm{a}}$ & $74.1(20 / 27)^{\mathrm{a}}$ & $77.8(21 / 27)^{\mathrm{a}}$ \\
\hline
\end{tabular}

\section{Discussion}

The present study experimentally evaluated the protective ability of aroA mutant $E$. coli vaccine against homologues (O78) and heterologous $(\mathrm{O} 125)$ E. coli challenge in broiler chickens, with focusing on their immune response against this vaccine as well as the bacterilogical characters of both the vaccinal strain versus the virulent field strains of E. coli.

Comparative bacteriological examination in this study demonstrated that aroA mutant $E$. coli vaccinal strain was similar to the virulent E. coli $\mathrm{O} 78$ strain in respect of colony morphology, biochemical reactions, Congo Red binding and motility but differed in antimicrobial sensitivity pattern as well the inability of vaccinal strain to grow on minimal agar medium, in contrast the virulent strain was able to grow. Similar findings were previously reported [6].

This study indicated that, the aroA mutant E. coli vaccine was safe in chickens as it had no drawbacks on chicken's performance or livability, this is in agreement with other studies [21-24]. As well, vaccination had no adverse effect on chickens' body weight during the experimental period. Similarly, Salehi et al. [21] and Moemen et al. [24] found the same data, in contrast Fernandes Filho et al. [11] registered a unique drawback for aroA mutant $E$. coli vaccine as it significantly reduced the weight gain of the immunized broilers compared to controls.
The leukogram results of this study showed that there were no significant differences between total or differential leukocytes count during the first three weeks old of vaccinated and non-vaccinated groups. In spite of somewhat slightly increased in total leukocytic count and heterophile \% in control group, conversely somewhat slightly increased in lymphocyte \% in vaccinated groups, such data was confirmed by Fernandes Filho et al. [11] who found that the total blood leukocytic count remained similar between groups throughout the experiment, except for day 1 pv, when the control group showed increased levels of total leukocytes, followed by the group that received antibiotic with the vaccination followed by the vaccine group. A differential count of the cells on day 1 showed that this leukocytosis was greatly due to heterophilia.

For evaluation of humoral immunity against aroA mutant $E$. coli vaccine, immunoglobulin levels in serum were evaluated by agglutination test and agglutination neither occurred in vaccinated nor non-vaccinated groups at 1,7,14 and 21 days post vaccination. Another study, that was working with an aroA mutant strain for the purpose of vaccination in chickens and could not find any changes in circulating antibody concentrations [21]. During another work, the high response of B lymphocytes that was observed in the control group, only on the $14^{\text {th }}$ day pv supported the proposal that the protection provided by vaccination does not depend on the production of antibodies [11]. 
It has been shown that $\mathrm{CD}^{+}$and $\mathrm{CD}^{+}$ cells are crucial to prevent $E$. coli translocation from the gut to other parts of the body [25]. In this study, using flow cytometery technique CD4 and CD8 in peripheral blood were measured for assessment cell mediated immunity against aroA mutant $E$. coli vaccine. The administration of vaccine either once or twice doses induced an early increase in the number of CD4 and CD8, this increase was significantly observed on day 14 and 21 post vaccination. These observations are agreed with Fernandes Filho et al. [11] who found the levels of $\mathrm{CD} 4^{+} \mathrm{TCRV} \beta 1^{+}$were significantly increased in the vaccinated group on days 14 and $21 \mathrm{pv}$, which likely induces an increase in the amount of secreted $\operatorname{IgA}$. The $\mathrm{CD} 4^{+} \mathrm{TCRV} \beta 1^{+}$subset comprises cells that assist the production of $\operatorname{IgA}$ antibody in the mucosa and are involved in protection against Newcastle virus and Mycoplasma gallisepticum, for instance [26,27].

Also, Fernandes Filho et al. [11] added that, the administration of the vaccine induced an early increase in the number of CD8 lymphocytes (on day 1 post vaccination) and the levels of $\mathrm{CD} 8^{+} \mathrm{CD} 28^{+}$cells, which comprise cells in the early stage of activation and memory and naive cells, that are increased in the peripheral blood of vaccinated animals only on the last two collection dates, being statistically significant on day $21 \mathrm{pv}$.

The CD4:CD8 ratio is hypothesized in the literature as a measure of immune system status in humans. A high ratio is associated with better immune responsiveness, whereas a low ratio, shown during aging in humans, for instance, means overall reduced immune response [28, 29 and 30]. In this study, the ratio of CD4:CD8 was marginally higher in the vaccinated once or twice groups compared to the control group especially at 14 and 21 day pv, indicating a higher cell mediated immune capacity, similar data found by Fernandes Filho et al. [11].

In the present study, there were statistical significant differences in minimizing mortality rate, lesions and bacterial re-isolation between the vaccinated groups and control one when homologous challenge (E. coli O78) occurred. These findings are similar with other studies $[6,24,31]$. In contrast to these findings, Salehi et al. [21] reported that mutant E. coli vaccination had no significant value versus homologous challenge.

In the present study, dissimilarly, there were no statistical significant differences in mortality rate, lesions or bacterial re-isolation between the vaccinated groups even once or twice and control group when heterologous challenge (E. coli O125) occurred even though there are somewhat minimizing rates in macroscopic lesions and bacterial re-isolation between vaccinated groups and non-vaccinated one. Similar reports of the current study reported that protection against APEC homologous challenge was achieved however protection against heterologous challenge could not achieved [22, 24, 32]. Our results disagreed with that obtained by La Ragione et al. [6] who reported that the aroA construct was shown to be successful as a vaccine against colibacillosis in chickens and turkeys caused by an untypeable APEC strain as an example for heterologous challenge.

\section{Conclusion}

In conclusion, spraying aroA mutant $E$. coli vaccine in broiler chickens is able to protect against APEC O78 through minimizing both mortality rate and collibacillosis lesions as well bacterial re-isolation. Further investigations may be required to reveal the protective efficacy of live attenuated aroA mutant $E$. coli vaccine against wide variety of recently predominant avian pathogenic E. coli strains isolated from Egypt.

\section{Conflict of interest}

The authors declare no conflict of interest.

\section{References}

[1]La Ragione, R.M. and Woodward, M.J. (2002): Virulence factors of Escherichia coli serotypes associated with avian colisepticaemia. Res Vet Sci, 73(1): 27-35.

[2]Dho-Moulin, M. and Fairbrother, J.M. (1999): Avian pathogenic Escherichia coli (APEC). Vet Res, 30(2-3): 229-316.

[3]Barnes, H.J.; Nolan, L.K. and Vaillancourt, J.P. (2008): Colibacillosis. In: Disease of poultry, 12th ed. Y. M. Saif, A. M. Fadly, V. R. Glisson, L. R. McDougald, L.K. 
Nolan and D. E.Swayne, eds. Blackweel Publishing, Ames, IA. 691:691-723.

[4]Johnson, T.J.; Johnson, S.J. and Nolan, L.K. (2006): Complete DNA sequence of a ColBM plasmid from avian pathogenic Escherichia coli suggest that it evolved from closely related ColV virulence plasmids. J Bacteriol, 188(16): 5975-5983.

[5]Cottarel, G. and Wierzbowski, J. (2007): Combination drugs, an emerging option for antibacterial therapy. Trends Biotechnol, 25(12): 547-555.

[6] La Ragione, R.M.; Woodward, M.J.; Kumar, M.; Rodenberg, J.; Fan, H.; Wales, A.D. and Karaca, K. (2013): Efficacy of a live attenuated Escherichia coli O78:K80 vaccine in chickens and turkeys. Avian Dis 57(2): 273-279.

[7]Lynne, A.M.; Foley, S.L. and Nolan, L.K. (2006): Immune response to recombinant Escherichia coli Iss protein in poultry. Avian Dis, 50(2): 273-276.

[8]Lynne, A.M.; Kariyawasam, S.; Wannemuehler, Y.; Johnson, T.J.; Johnson, S. J.; Sinha, A.S., et al., (2012): Recombinant Iss as a potential vaccine for avian colibacillosis. Avian Dis, 56(1): 192-199.

[9]Chaffer, M.; Schwartsburd, B. and Heller, E.D. (1997): Vaccination of turkey poults against pathogenic Escherichia coli. Avian Pathol, 26(2): 377-390.

[10]Tivendale, K.A.; Logue, C.M.; Kariyawasam, S.; Jordan, D.; Hussein, A.; Li, G. et al., (2010): Avian pathogenic Escherichia coli strains are similar to neonatal meningitis E. coli strains and are able to cause meningitis in the rat model of human disease. Infect Immun, 78(8): 3412-3419.

[11] Fernandes Filho, T.; Fávaro, C.; Ingberman, M.; Beirão, B.C.; Inoue, A.; Gomes, L. and Caron, L.F. (2013): Effect of spray Escherichia coli vaccine on the immunity of poultry. Avian Dis, 57(3): 671-676.

[12] Roland, K.; Curtiss, R. and Sizemore, D. (1999): Construction and evaluation of a delta cya delta crp Salmonella
Typhimurium strain expressing avian pathogenic Escherichia coli O78 LPS as a vaccine to prevent airsaculitis in chickens. Avian Dis, 43(3): 429-441.

[13] Roland, K.; Karaca, K. and Sizemore, D. (2004): Expression of Escherichia coli antigens in Salmonella Typhimurium as a vaccine to prevent airsaculitis in chickens. Avian Dis,48(3): 595-605.

[14] Ghunaim, H.; Abu-Madi, M.A. and Kariyawasam, S. (2014): Advances in vaccination against avian pathogenic Escherichia coli respiratory disease: potentials and limitations. Vet Microbiol, 172(1-2): 13-22.

[15] Cruickshank, R.; Duguid, J.P.; Marmion, B.P. and Swain, R.H.A. (1975): Medical Microbiology, 12th ed., Vol. II Churchill living stone, Edenburg, London and New York.

[16] Hemalatha, V.; Padma, M.; Uma, S.; Vinodh, T.M. and Arunkumar, A.S. (2006): Detection of ampC beta lactamase production in Escherichia coli \& Klebsiella by an inhibitor based method. Indian J Med Res, 126: 220-223.

[17] La Ragione, R.M.; Cooley, W.A. and Woodward, M.J. (2000): The role of fimbriae and flagella in adherence of avian strains of the Escherichia coli O78:K80 to tissue culture cells and tracheal and gut explants. J Med Microbiol, 49(4): 327-338.

[18] Allen-Vercoe, E. and Woodward, M. J. (1999): The role of flagella, but not fimbriae, in the adherence of Salmonella enterica serotype Enteritidis to chickgut explant. J Med Microbiol, 48(8): 771780.

[19]Anthony, T.W.C.; Twin, K.M.L.; Erin, M.W. and Michael, E.M. (1985): Phagocytic and killing capacities of uterine derived leukocytes from mare resistance and susceptible to chronic endometeritis. Am J Vet Res, 46(9):1938:1940.

[20]Chu, Y. and Dietert, R.R. (1989): Monocytes function in chicken with hereditary dystrophy. Poult Sci, 68(2):226-232. 
[21]Salehi, T.Z.; Tabatabaei, S.; Karimi, V.; Fasaei, B.N.; Derakhshandeh, A. and Jahromi, O.N. (2012): Assessment of immunity against avian colibacillosis induced by an Aroa mutant containing increased serum survival gene in broilers. Braz J Microbiol, 43(1):363370.

[22]Peighambari, S.M.; Hunter, D.B.; Shewen, P.E. and Gyles, C.L. (2002): Safety, immunogenicity, and efficacy of two Escherichia coli cya crp mutants as vaccines for broilers. Avian Dis, 46(2): 287-297.

[23]Kariyawasam, S.; Wilkie, B.N. and Gyles, C.L. (2004a): Construction, characterization, and evaluation of the vaccine potential of three genetically defined mutants of avian pathogenic Escherichia coli. Avian Dis, 48(2): 287299.

[24]Moemen, A. M.; Bakhit, M. B.; Awad, A. I. and Mohamed, S. (2016): Evaluation of the living Escherichia coli-O78 deleted aroA vaccine against homologous and heterologous E. coli challenge in broiler chickens. Journal of Advanced Veterinary Research 6(3): 8992.

[25]Gautreaux, M.D.; Gelder, F.B.; Deitch, E.A. and Berg, R.D. (1995): Adoptive transfer of $\mathrm{T}$ lymphocytes to T-celldepleted mice inhibits Escherichia coli translocation from the gastrointestinal tract. Infect Immun, 63(10):3827-3834.

[26]Cihak, J.; Hoffmann-Fezer, G.; ZieglerHeibrock, H.W.; Stein, H.; Kaspers, B.; Chen, C.H., et al., (1991): T cells expressing the $\mathrm{V}$ beta $1 \mathrm{~T}$-cell receptor are required for $\operatorname{IgA}$ production in the chicken. Proc Natl Acad Sci U. S. A., 88:10951-10955.

[27]Smialek, M.; Tykalowski, B.; Stenzel, T. and Koncicki, A. (2011): Local immunity of the respiratory mucosal system in chickens and turkeys. Pol J Vet Sci, 14(2):291-297.

[28]Pawelec, G.; Akbar, A.; Caruso, C.; Effros, R.; Grubeck-Loebenstein, B. and Wikby, A. (2004): Is immunosenescence infectious? Trends Immunol, 25:406410.

[29]Bridle, B.W.; Julian, R.; Shewen, P.E.; Vaillancourt, J.P. and Kaushik, A.K. (2006): T lymphocyte subpopulations diverge in commercially raised chickens. Can J Vet Res, 70(3):183-190.

[30]Fair, J.M.; Taylor-McCabe, K.J.; Shou, Y. and Marrone, B.L. (2008): Immunophenotyping of chicken peripheral blood lymphocyte subpopulations: individual variability and repeatability. Vet Immunol Immunopathol, 125(3-4):268-273.

[31]Sadeyen, J.R.; Wu, Z.; Davies, H.; van Diemen, P.M.; Milicic, A.; La Ragione, R.M., et al., (2015): Immune responses associated with homologous protection conferred by commercial vaccines for control of avian pathogenic Escherichia coli in turkeys. VetRes, 46 (1): 1-14.

[32]Peighambari, S. M. and Gyles, C. L. (1998): Construction and characterization of avian E. coli cya crp mutants. Avian Dis, 42(4):698-710. 


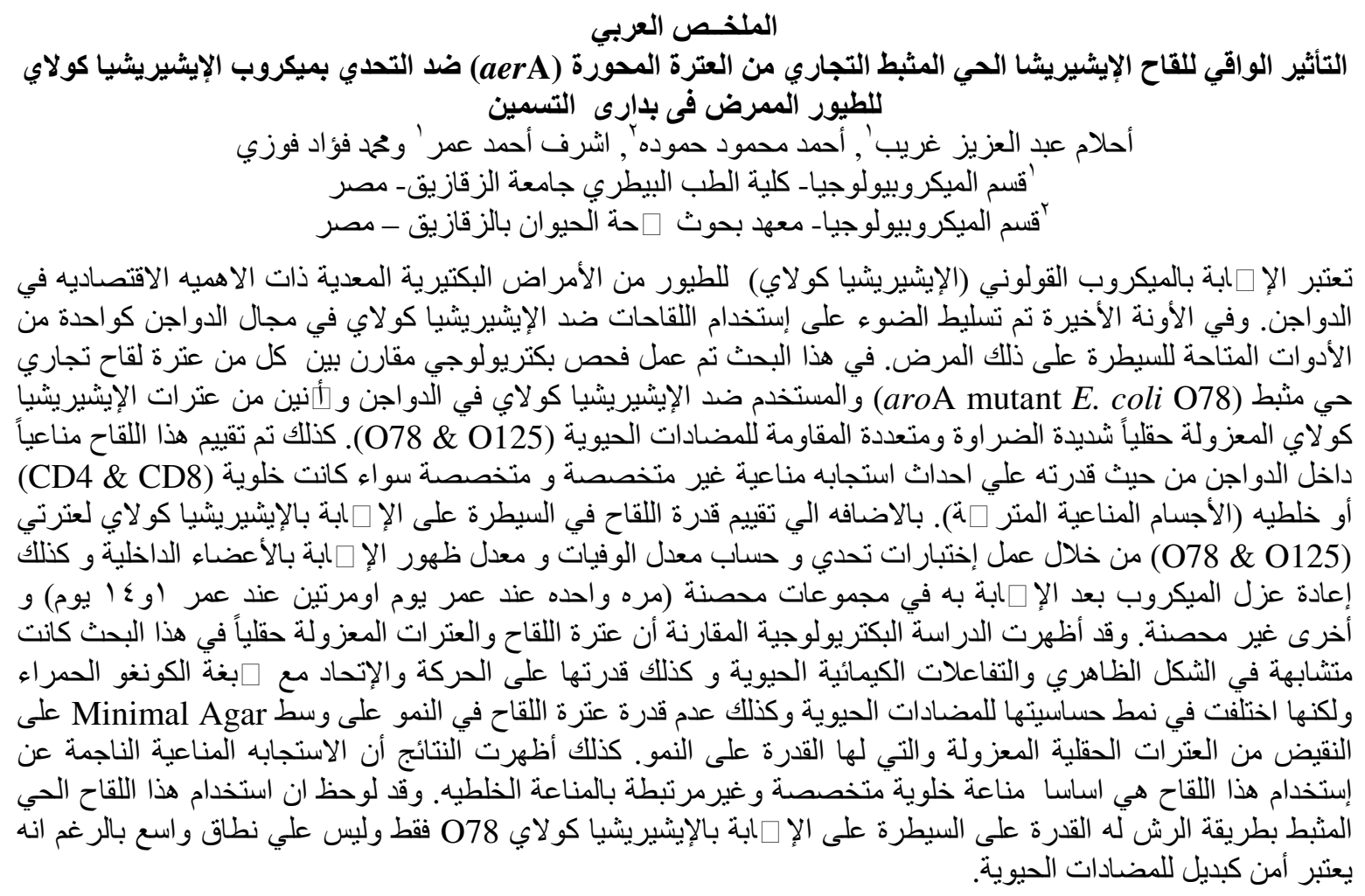

